\title{
Giant Pediatric Omental Cyst: A Case Report and Review of Literature
}

\author{
Amit Kumar Sinha ${ }^{1}$, Maheshkumar Manilal Vaghela ${ }^{2}$, Kajal Sinha $^{3}$, Bindey Kumar $^{4}$, Prem Kumar $^{5}$ \\ ${ }^{1}$ MBBS, MS, M Ch, Senior Resident, Department of Pediatric surgery, AIIMS Patna \\ ${ }^{2}$ MBBS, MS, M Ch, Senior Resident, Department of Pediatric surgery, AIIMS Patna \\ ${ }^{3}$ MBBS, MS, Senior Resident, Department of Obstetrics and Gynaecology
}

${ }^{4}$ MBBS, MS, M Ch, DNB, MNAMS, Professor and Head, Department of Pediatric Surgery, AIIMS Patna

${ }^{5}$ MBBS, MD, Professor and Head, Department of Radiology, AIIMS Patna

\begin{abstract}
Omental cyst is rare congenital anamoly of gastrointestinal tract. It is represented as abdominal distension. Occasionally, it may be presented with acute abdomen due to twisting of omental cyst and omentum and other complications. The ultrasonography and CECT abdomen are useful to make diagnosis of abdominal cyst. Complete surgical excision of cyst is definitive treatment. We are presenting a case of giant omental cyst in a pediatric female patient aged 3 year and 6months.
\end{abstract}

Keywords: Giant omental cyst; Abdominal cyst; Ascites; Mesenteric cyst; Ovarian cyst

\section{Case Report}

We are presenting a case of giant multiloculated omental cyst in 3 year and 6 month old female patient. She visited to outpatient department with complain of abdominal distension since 7 month. The distension was gradually increasing. Patient was having mild abdominal discomfort. She was taking feed regularly and did not have any bowel, bladder or respiratory complains. On general examination, no obvious other abnormalities were detected. On systemic examination, abdomen was grossly distended. On palpation, no obvious localized mass or other abnormality were detected. Fluid thrill was present. Patient was evaluated by routine and diagnostic investigations. Complete blood report was within normal limit. Plain abdomen radiograph was suggestive of haziness of abdomen with paucity of intestinal gas. The ultrasonography of the abdomen was suggestive of large multi-loculated cystic lesion in anterior part of abdomen extending from epigastrium to pelvis with posterior displacement of bowel loops. A differential diagnosis of mesenteric, omental or ovarian cyst was made. CECT abdomen was done suggestive of large multicoculated cystic lesion occupying almost all compartments of the abdomen. The whole small intestine was displaced posterior by the cyst (Figure 1). On the view of clinical and radiological investigation, laparotomy was planned. Laparotomy was done by right upper transverse incision. There was large multiloculated omental cyst almost occupying whole abdomen cavity. Whole omental cyst delivered through incision outside by gentle manipulation. Twisting of omentum and its vessel was present (Figure 2). The cyst was covered by thin layer of omentum from all around. Small part of omentum near transverse colon was spared. Omentum near to cyst ligated and giant omental cyst was excised. No obvious other abnormality was detected. Specimen sent for histo-pathological diagnosis. Postoperatively, patient was stable and discharged on $3^{\text {rd }}$ postoperative day.

\section{Discussion}

The omental cysts are rare congenital anomaly. It is less common than mesenteric cyst. It is more common in pediatric population compare to adult. The incidence of omental and mesenteric cyst is 1:20000 in pediatric population [1]. The first case of an omental cyst was reported by Gairdner in 1852 [2]. The different theories are given for omental cyst formation. These are (a) failure of the embryonic spaces to join with the venous system (b) failure of leaves of mesentery to fuse $(\mathrm{C})$ occult trauma, neoplasia and localized degeneration of lymph nodes. The most commonly accepted theory is benign proliferation of ectopic lymphatic in the omentum which is lacking communication with the remainder lymphatics [3]. Omental cyst are located in the lesser and greater omentum [4]. In our case omental cyst was found within greater omentum with fully covered by omentum layers. They are mostly lymphatic cyst. The omental cyst are multicolucular or unilocular and mostly contain serous fluid. Sometimes hemorrhagic, chylous or infected fliud can be detected [5, 6]. Our patient had multilocular cyst with size of 30x25 cm with almost 8 liters of fluid. The fluid was brownish serous color. The epithelial lining of omental cyst would be cuboidal or columnar. They are mostly incidentally detected during laparoscopy or laparotomy performed for another causes. They may present in acute life threatening condition due to omental cyst and omentum twisting. Complication associated with omental cyst include intestinal obstruction, volvolus, hemorrhage into cyst, infection, rupture, torsion of the cyst. On chronic cases, they may present as progressive distension of abdomen with or without a palpable mass and pain. The definitive mass may be difficult to palpate. The mass may be large and filling the abdomen cavity mimicking ascites. Omental cyst can be distinguished from ascites by the relative sparing of flank region bulge [7]. If definitive mass palpable, omental cyst are movable in the transverse and cranio-caudal planes. Plain abdomen radiograph may show 


\section{International Journal of Science and Research (IJSR) \\ ISSN (Online): 2319-7064 \\ Index Copernicus Value (2013): 6.14 | Impact Factor (2015): 6.391}

gasless, homogenous mass with displaced bowel loops. The abdomen ultrasound is first choice of investigation which showing a well circumscribed thin walled fluid filed cystic structure with internal septa and sometimes internal echoes [8]. The CECT abdomen shows definite origin of cyst and relation to surrounding structure especially intestine. It differentiates other cyst arising from ovary, kidney or pancreas [9]. The complete surgical excision is treatment of choice.

\section{Conclusion}

Giant omental cyst is rare congenital anomaly. It is difficult to distinguish from mesenteric cyst. The complete surgical excision is modality of treatment. This case report helps to keep this clinical entity as differential diagnosis of gross abdominal distension due to ascites or other abdominal cystic lesion

\section{References}

[1] Walker AR, Putnam TC: Omental, mesenteric and retroperitoneal cyst. A clinical study of 33 new cases. Ann Surg 1973, 178:13-9.
[2] Gairdner WT: A remarkable cyst in the omentum. Trans Path Soc Lond 1852; 3:1851

[3] Egozi EI, Ricketts RR: Mesentric and omental cysts in children. Am Surg 1997; 63:287-90

[4] Conzo G, Vacca R, Esposito M Grazia, Brancaccio U, Celsi S, Livrea A. Laparoscopic treatment of an omental cyst: a case report and review of the literature. Surg Laparosc Endosc Percutan Tech 2005; 15:33-5.

[5] Moralioglu S, Sonmez K, Turkyilmaz Z, Basaklar AC, Kale N. A child with a giant omental cyst. Acta Chir Belg 2007; 107:724-5.

[6] Hebra A, Brown MF, McGeehin KM, Ross AJ $3^{\text {rd }}$ Mesentric, omental and retroperitoneal cysts in children: a clinical study of 22 cases. South Med J 1993; 86:1736.

[7] Iu Devrim Karaosmanog, Oktar Suna O zhan,Cem Yu, Zdemir Hakan O: Huge omental cyst simulating ascites. European Journal of Radiology Extra 2005; 54:55-57.

[8] Nett MH, Vo NJ, Chapman T. Large omental cyst. Radiol Case Rep 2010; 5:388

[9] Kumar S, Agrawal N, Khanna R, Khanna A K. Giant lymphatic cyst of omentum: a case report. Cases J 2009; $2: 23$.

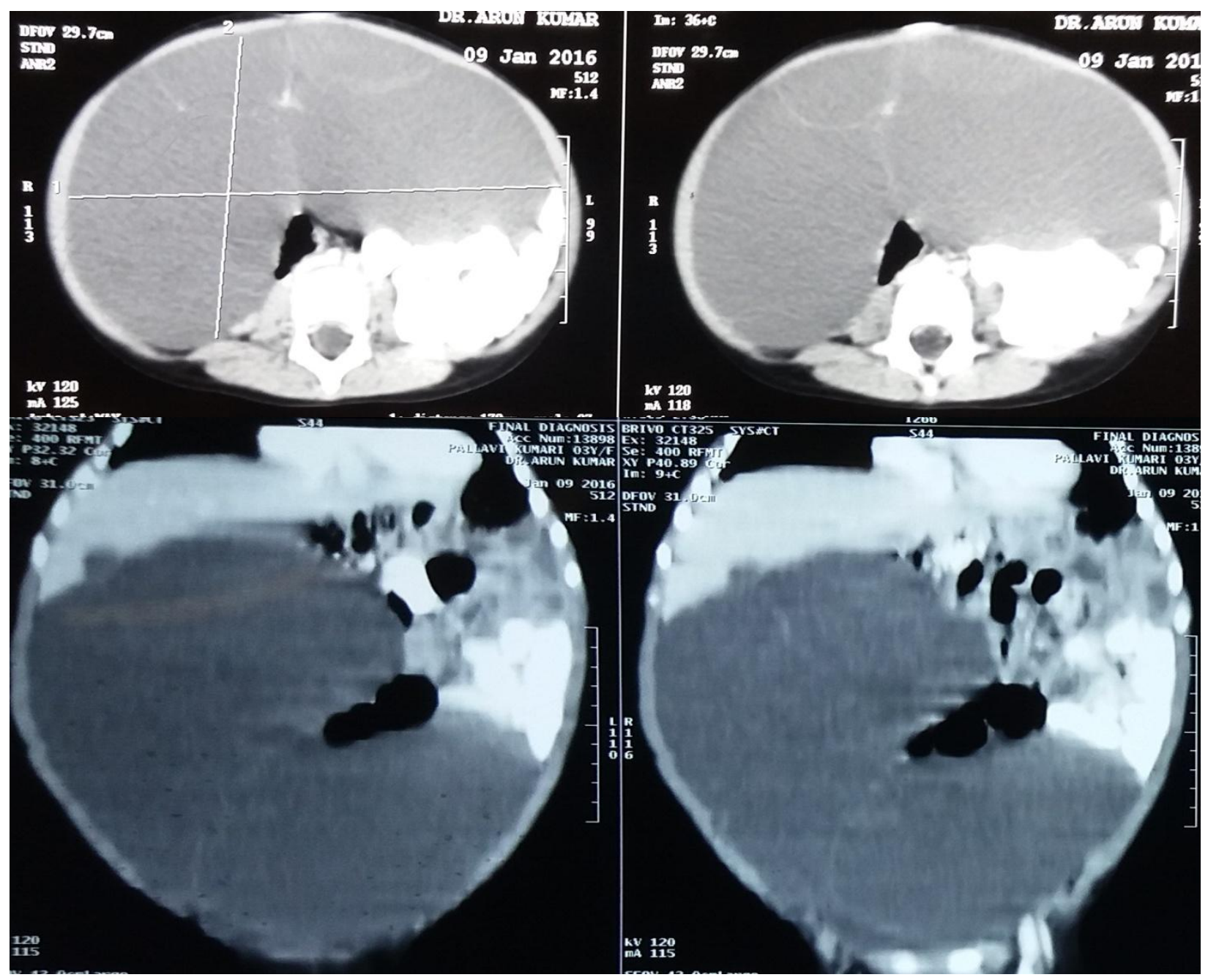

Figure 1: CECT abdomen showing large multiloculated cyst 
International Journal of Science and Research (IJSR)

ISSN (Online): 2319-7064

Index Copernicus Value (2013): 6.14 | Impact Factor (2015): 6.391

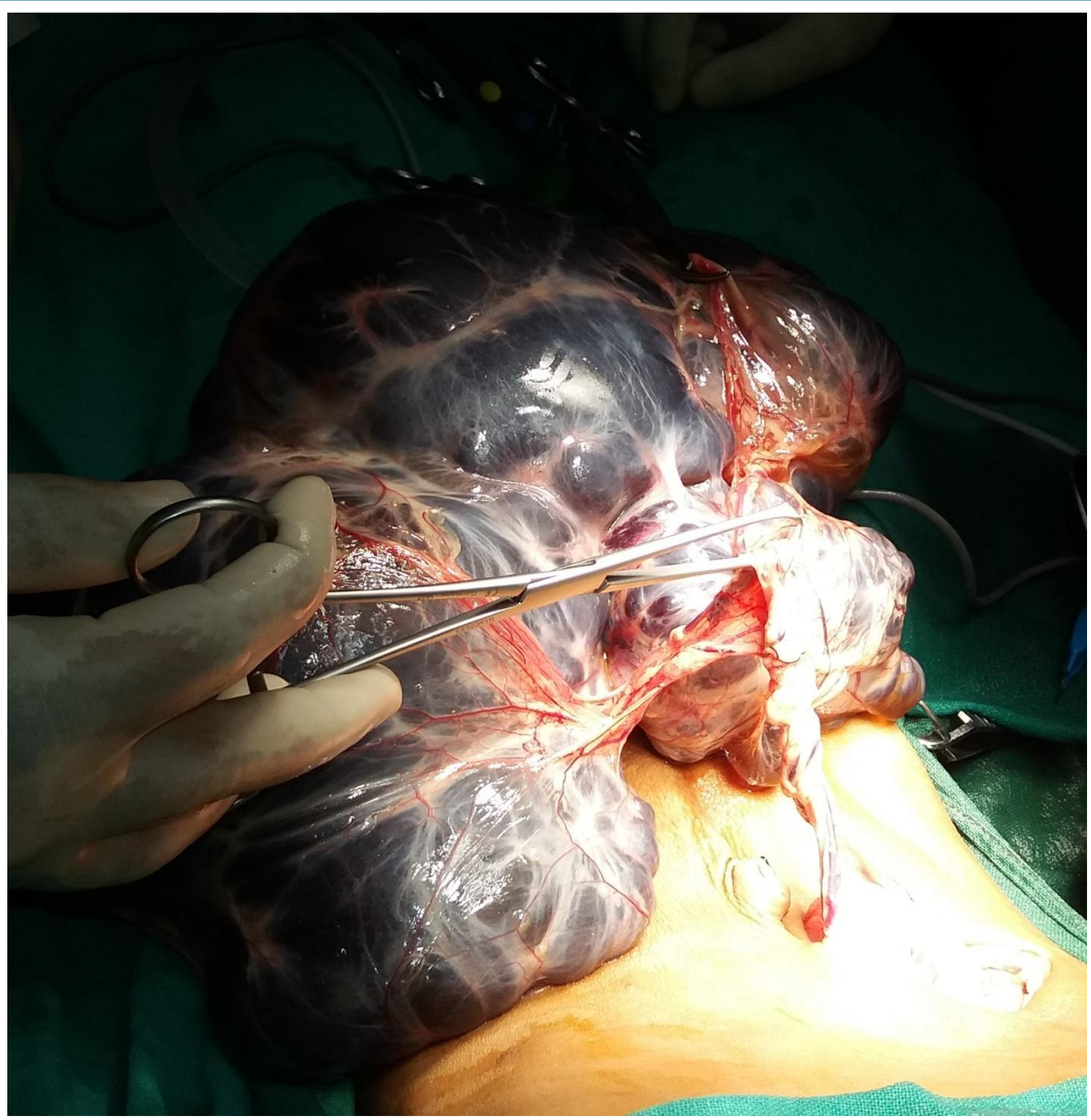

Figure 2: Giant omental cyst with twisted omentum

Volume 5 Issue 6, June 2016 www.ijsr.net

Licensed Under Creative Commons Attribution CC BY 